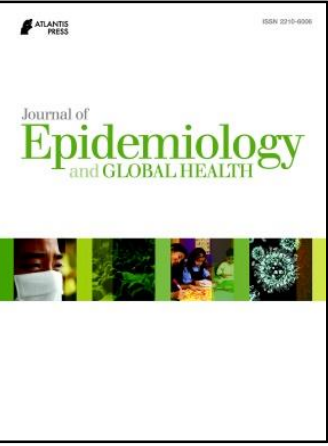

\title{
Journal of Epidemiology and
} Global Health

ISSN (Online): 2210-6014 ISSN (Print): 2210-6006

Journal Home Page: https://www.atlantis-press.com/journals/jegh

\section{Corrigendum to "Correlates of health attitudes among homosexual and bisexual men" [J. Epidemol. Global Health 3(1) (2013) 31-39]}

Deborah A. Gust, Sanjyot Shinde, Sherri L. Pals, Felicia Hardnett, Robert T. Chen, Travis Sanchez

To cite this article: Deborah A. Gust, Sanjyot Shinde, Sherri L. Pals, Felicia Hardnett, Robert T. Chen, Travis Sanchez (2013) Corrigendum to "Correlates of health attitudes among homosexual and bisexual men" [J. Epidemol. Global Health 3(1) (2013) 31-39], Journal of Epidemiology and Global Health 3:4, 293-293, DOI:

https://doi.org/10.1016/j.jegh.2013.09.005

To link to this article: https://doi.org/10.1016/j.jegh.2013.09.005

Published online: 23 April 2019 


\title{
Corrigendum to "Correlates of health attitudes among homosexual and bisexual men"' [J. Epidemol. Global Health 3(1) (2013) 31-39]
}

\author{
Deborah A. Gust ${ }^{a, *}$, Sanjyot Shinde ${ }^{a}$, Sherri L. Pals ${ }^{b}$, Felicia Hardnett ${ }^{a}$, \\ Robert T. Chen ${ }^{a}$, Travis Sanchez ${ }^{a}$
}

${ }^{a}$ Division of HIVIAIDS Prevention, National Center for HIVIAIDS, Viral Hepatitis, STD, and TB Prevention, Centers for Disease Control and Prevention, Atlanta, GA, United States

${ }^{\mathrm{b}}$ Center for Global Health, Centers for Disease Control and Prevention, Atlanta, GA, United States

The author regrets to inform that there was an incorrect message in the abstract and the correct abstract should be:

There is increased emphasis on physician attention to the overall health and wellness of homosexual and bisexual men, though little is known about the health-related attitudes of these groups. This study determined factors associated with the health attitudes of homosexual and bisexual men and identified preferred sources of health information. For this study, the 2008 ConsumerStyles panel survey was used to create three health attitude scales and to determine factors associated with each scale. The three scales were labeled: (1) health motivation; (2) relationship with health care provider; and (3) self-perception of health literacy. In addition to other factors, higher scores for health motivation and relationship with health care provider were associated with black compared with white men. In contrast, lower scores for selfperception of health literacy were associated with black compared with white men. For information on an unfamiliar health condition, most homosexual and bisexual men chose the internet. Black homosexual and bisexual men reported being motivated to be healthy and working well with their health care provider to manage their health. However, their perception of their own health literacy was low compared with the white men. Attempts to improve health literacy through internet sites may be helpful in improving health attitudes and reducing negative health outcomes.

\footnotetext{
DOI of original article: 10.1016/j.jegh.2012.12.006.

* Corresponding author. Address: Epidemiology Branch, Division of HIV/AIDS Prevention, CDC, 1600 Clifton Rd., Mail-Stop E-45, Atlanta, GA 30333, United States. Tel.: +1 404639 8841; fax: +1 4046396127.

E-mail address: dgust@cdc.gov (D.A. Gust).
} 